\title{
AS CONSTRUÇÕES MÉDIAS NOS ARTIGOS CIENTÍFICOS DE LINGUÍSTICA
}

\author{
(The middle constructions in scientific \\ articles in Linguistic)
}

Fernanda Beatriz Caricari de Morais ${ }^{1}$ (Pontifícia Universidade Católica - PUC/SP)

\begin{abstract}
This article analyses the middle constructions used in scientific articles in Linguistic, randomly collected from Scielo platform. According to the ergative perspective (Halliday 1985, 1994) and Halliday \& Matthiessen (2004), the constructions found are analyzed, describing the choices of Medium in the context use in the articles. The constructions were obtained by the use of a computer program that can be used with a large number of texts. The analysis shows that the ergative constructions are used in different sections in the articles, hiding the identity of the author or others mentioned in the texts.
\end{abstract}

Key-words: middle constructions, clitic 'se', systemic functional linguistics.

\section{RESUMO}

Este artigo analisa as construções médias utilizadas em artigos científicos da área de Linguística, coletados aleatoriamente da plataforma Scielo. Com base na perspectiva da ergatividade (Halliday 1985, 1994) e Halliday \& Matthiessen (2004), as construções encontradas são analisadas, procurando descrevê-las com base nas escolhas dos Meios e no contexto em que ocorrem nos artigos. As ocorrências foram obtidas através do uso de ferramentas computacionais que possibilitam o trabalho com grande número de textos. A análise revela que essas construções são utilizadas em diferentes seções para se apagar a identidade do autor ou de outros autores citados nos textos.

1. Graduada em Letras - Inglês/Português - pela Pontifícia Universidade Católica de Campinas. Possui Mestrado e Doutorado em Linguística Aplicada e Estudos da Linguagem pela Pontifícia Universidade de São Paulo (PUC-SP/CNPq) sob orientação da Profa. Dra. Leila Barbara. 
Palavras-chave: construções médias, clítico 'se', Linguística SistêmicoFuncional.

\section{Introdução}

Neste artigo, busca-se descrever e analisar como as construções médias são utilizadas em um corpus formado por 30 artigos científicos da área de Linguística, escritos em língua portuguesa. Esses artigos foram coletados aleatoriamente do SciELO, plataforma digital que contém periódicos nacionais bem avaliados pela Qualis². Procurouse coletar artigos dos últimos cinco anos de um periódico da área de Linguística com nota A na avaliação.

O que motivou este estudo foi a pesquisa de doutorado (Morais, 2013) que teve como foco o uso do clítico 'se' em artigos científicos de diversas áreas do conhecimento. Nessa pesquisa, foram analisadas construções com esse clítico, com exceção do uso reflexivo e condicional, visando compreender como os autores as utilizam para apagar sua participação nos textos. Dentre as estruturas utilizadas, uma delas é a construção média, caracterizada por representar eventos espontâneos, representando-os como se tivessem ocorrido sem a participação de um Agente. A referida tese, bem como este artigo, está inserida em um contexto mais amplo, o projeto SAL (Systemics Across Languages), desenvolvido em parceria com pesquisadores da China, Argentina, México e Tailândia que procuram entender as características específicas e universais que partilham as línguas.

No Brasil, esse projeto visa estudar a linguagem de artigos científicos. Dentre as pesquisas realizadas, destacam-se a de Barbara \& Macedo (2010) que estudaram o uso de processos verbais em artigos de diversas áreas do conhecimento, Moyano (2010) que

2. A nota Qualis é uma classificação feita pela CAPES dos veículos utilizados pelos programas de pós-graduação para a divulgação da produção intelectual de seus docentes e alunos, cujo objetivo é atender às necessidades específicas da avaliação da pós-graduação realizada por esta agência. 
estudou a discussão de um artigo da área de agronomia por meio do subsistema de engajamento (Martin \& White, 2005), Vivan (2010) que analisou artigos científicos de Linguística Aplicada com foco nas metáforas interpessoais e em processos verbais, Morais (2010) que realizou um estudo comparativo de conclusões de artigos científicos de duas áreas distintas - Odontologia e Linguística, mostrando as preferências léxico-gramaticais e as especificidades dessas áreas, entre outros pesquisadores.

Neste artigo, primeiramente, a teoria de linguagem adotada, a Linguística Sistêmico-Funcional (doravante LSF) de Halliday (1985, 1994) e Halliday \& Matthiessen (2004) é apresentada com foco na perspectiva da ergatividade, base da análise das ocorrências extraídas pelas ferramentas do programa WordSmith Tools (Scott, 2008), que fornecem dados estatísticos e listas com a palavra de busca destacada (neste caso, o clítico 'se'), maiores detalhes descritos nos procedimentos metodológicos. As ocorrências obtidas são analisadas com foco nos seus contextos de uso e nas seções dos artigos em que ocorrem, para assim compreender como as construções médias podem ser utilizadas no gênero artigo científico, mais especificamente, no compus de estudo desta pesquisa.

\section{A visão de linguagem segundo a Linguística Sistêmico-Funcional}

A LSF tem como foco a linguagem em uso e seus princípios teóricos enfatizam o ambiente situacional e cultural no qual os textos são produzidos. A linguagem é vista como um evento interativo, como um processo, uma troca social de significados, em contextos específicos de situação. Conforme a referida teoria, a análise do discurso compreende dois níveis de alcance: o de contribuir para a compreensão do texto, visando mostrar como e por que o texto transmite significado da maneira como o faz; e o de se relacionar com a avaliação de texto, procurando mostrar por que um dado texto é ou não efetivo para os seus propósitos. 
As maneiras pelas quais as pessoas utilizam a linguagem para atingir determinados objetivos, em situações específicas, dentro de uma sociedade são o foco de estudo da LSF (Halliday 1985, p. 4). A linguagem é vista como um sistema de escolhas no qual os seres humanos criam significados. Quando um texto (oral ou escrito) é produzido, são realizados três tipos de significado simultaneamente. Significados relativos à representação da experiência através da língua; significados relativos às representações de poder e solidariedade, atitudes em relação ao outro e os papéis sociais assumidos e significados relativos à organização do conteúdo da mensagem, relacionando o que se diz ao que foi dito. Na LSF, cada um desses tipos de significado está relacionado a uma metafunção da linguagem ideacional, interpessoal e textual (Halliday, 1985 e 1994) e Halliday \& Matthiessen (2004).

\section{Ergatividade segundo a LSF}

A perspectiva da ergatividade é descrita, neste artigo, segundo a abordagem Sistêmico-Funcional. Sabe-se que há outras correntes teóricas que estudam a ergatividade em diversas línguas, como Anderson (1976), Dixon (1994) e Manning (1996), porém, optouse por utilizar a proposta de ergatividade de Halliday $(1985,1994)$ e Halliday \& Matthiessen (2004), como parte da metafunção ideacional, utilizada para enfocar o mundo, tanto externo (coisas, eventos, qualidades, etc.), como interno (pensamentos, crenças, sentimentos, etc.).

A metafunção ideacional pode ser explorada por dois aspectos: através da metafunção lógica, que fornece recursos para entender a complexidade da oração e da metafunção experiencial que é a estrutura funcional interna das configurações experienciais da oração. A realização desse sistema experiencial ocorre através do sistema da transitividade que permite distinguir nitidamente "aquele que faz" e "aquele a quem se faz".

No entanto, pode-se olhar essa distinção desde uma outra perspectiva, focalizando o fato de que os processos podem acontecer 
por si mesmos ou serem provocados. Essa perspectiva é chamada de ergatividade. Assim, há dois diferentes modos de modelar a transitividade - o modelo transitivo e o modelo ergativo.

Os dois modelos - transitivo e ergativo - são noções teóricas que servem para explorar as características da representação experiencial nas línguas. Caffarel (2006, p.60) sugere que a língua francesa pode ser vista pelas duas perspectivas e que a maioria dos processos pode ser usada em construções médias, como no exemplo a seguir:

\begin{tabular}{|c|c|}
\hline A interação & se desenvolveu (Delta007) \\
\hline Meio & Processo \\
\hline
\end{tabular}

Todo processo (verbo, em termos tradicionais) está associado a um participante (Agente) em particular, que é a figura-chave no processo, sem o participante não seria possível o processo existir. Esse participante, nas construções médias, é chamado de Meio, entidade pela qual o processo se realiza. É um participante obrigatório e, no exemplo acima, o Meio é a interação.

O núcleo da oração, formado pelo Processo e o Meio, é o que determina o alcance das opções disponíveis para o restante da oração. O exemplo seguinte representa um campo semântico pequeno que pode ser realizado por uma oração sozinha: A interação se desenvolveu, ou em conjunto com outros participantes ou funções circunstanciais: A interação se desenvolveu na sala de aula. Em que a circunstância de lugar (advérbio) a sala de aula foi acrescida.

O processo pode ser representado como causado por ele mesmo (self-engendering), porém Halliday \& Matthiessen (2004:290) discute que, no mundo real, há sempre uma causa externa, mas, na semântica da língua, a oração $A$ porta se fechou, por exemplo, é representada como causada por ela mesma.

Segundo o autor (op. cit.), provavelmente todos os sistemas transitivos, em todas as línguas, são uma mistura dos dois modelos semânticos - o transitivo e o ergativo. O ergativo é uma interpretação nuclear e uma oração sem característica de agenciação não é ativa, 
nem passiva, mas sim média. A oração com agenciação é não-média ou efetiva quanto à agenciação. A oração efetiva pode ser operativa ou receptiva em voz. Na oração operativa, o sujeito é o Agente e o Processo é realizado por um grupo verbal ativo. Na receptiva, o sujeito é o Meio e o Processo é realizado por um grupo verbal passivo: $A A C$ se filia a uma tradição hermenêutica.... (Delta027).

Os modelos ergativo e transitivo não representam diferentes formas de subcategorizar processos, mas formas complementares de construção da experiência em uma língua. O critério gramatical serve de suporte para a classificação dos processos em diferentes tipos semânticos.

A semântica do modelo ergativo é a causação (causation): "O Processo é representado como se tivesse ocorrido sozinho ou ocorreu pela ação de uma força externa?" (Halliday, 1985:147). Note-se que no primeiro exemplo ( $O$ experimento se desenvolveu) a natureza da própria produção do processo é explicitamente marcado pelo clítico 'se'. Segundo a perspectiva ergativa, a variável é a presença ou ausência do Agente. A oração que representa um processo causado por ele mesmo (self-caused process) sem o Agente é chamada de média. O núcleo da estrutura experiencial dessa oração é Processo + Meio. $\mathrm{O}$ Meio (A interação), participante mais nuclear, é o único participante em que o processo é realizado; é a função essencial para a realização de qualquer processo. De outra maneira, a oração que representa um processo trazido por alguma causa externa (por um Agente) é efetiva.

A semântica do modelo transitivo é a extensão: "O Ator (Agente, em termos tradicionais) está comprometido no processo? O processo se estende para além o Ator? para alguma outra entidade?", "O processo está direcionado a outro Participante?" (Halliday \& Matthiessen (2004:287)). Assim, nesta perspectiva, a variável é a presença ou não da Meta, como nos exemplos em que a Meta (objeto, em termos tradicionais) é a interação:

I. A interação se desenvolveu.

II. O professor desenvolveu a interação. 
A natureza produtiva do clítico permite que muitos verbos sejam utilizados em construções médias. Cafarrel (2006:61) aponta que essa é uma característica importante da língua francesa e que pode ser relacionada com uma mudança semântica na língua, do transitivo para o ergativo.

Acredita-se que essa relação ocorra também em língua portuguesa. Por isso, o interesse deste artigo é descrever o papel que o clítico 'se' desempenha, em uma amostra composta por artigos científicos da área de Linguística, na alternância entre os sentidos ergativo / não-ergativo. As construções médias são mais evidentes em alguns registros ou tipos de texto, conforme Halliday \& Matthiessen (2004:285) explicam. Por exemplo: na análise de registros científicos ou em "hard news" (reportagem de acidentes, desastres, etc.), a interpretação do Processo como tendo ou não um causador externo na combinação do Processo + Meio promove mais insight do que a interpretação do processo como extensão ou não além do Ator/Agente.

Ao analisar artigos do jornal Le Monde, Cafarrel (2006) descreve que todos os participantes humanos foram deixados de fora do texto. As orações passivas possuíam Agentes omitidos e as orações médias apresentavam Agentes inanimados. O uso dessas serve para dar um sentido de afastamento e não há força externa que possa parar o processo.

\section{Metodologia}

Nesta subseção, primeiramente, são apresentados os procedimentos de coleta e organização dos dados para, em seguida, descrever as ferramentas computacionais do programa WordSmith Tools (Scott, 2008), utilizado para o tratamento das ocorrências e, por fim, a metodologia de análise é descrita com suporte teóricometodológico da Linguística Sistêmico- Funcional. 


\subsection{O corpus de estudo}

Os artigos foram coletados na plataforma digital Scielo.br (Scientific Eletronic Library Online), que é um banco de dados que contém revistas científicas de diversas áreas. Foi selecionado um dos periódicos da área da Linguística com melhor nota no Qualis, a Revista de Documentação de Estudos em Linguistica Teórica e Aplicada (D.E.L.T.A.), para serem coletados aleatoriamente 30 artigos escritos em língua portuguesa.

Cada artigo foi salvo em um arquivo individual do programa word, foram excluídas: figuras, gráficos, quadros, palavras-chaves, abstracts e referências bibliográficas, por não serem objetos deste artigo. $\mathrm{O}$ formato em que os artigos foram gravados foi o $t x t$, formato esse que permite a utilização do programa WordSmith Tools (Scott, 2008).

Esse programa possibilitou a obtenção de dados estatísticos do corpus de estudo, como mostra a Tabela 1 a seguir.

\section{Tabela 1: Características dos corpora}

\begin{tabular}{|l|l|}
\hline Estatística & Revista Delta \\
\hline Total de artigos & 30 \\
\hline Total de palavras & 234.099 \\
\hline Palavras diferentes & 17.124 \\
\hline No. de palavras do menor artigo & 3.440 \\
\hline No. de palavras do maior artigo & 13.822 \\
\hline Total de ocorrências do clítico 'se' & 2.977 \\
\hline $\begin{array}{l}\text { Total de ocorrências do clítico 'se' } \\
\text { em } \%\end{array}$ & $1.28 \%$ \\
\hline
\end{tabular}

Os dados exibidos na Tabela 1, acima, foram retirados dos números estatísticos da ferramenta wordlist do programa WordSmith Tools (Scott, 2008), apresentado em maiores detalhes a seguir. 


\subsection{A utilização do programa WordSmith Tools}

O instrumento computacional utilizado em Linguística de Corpus (LC), WordSmith Tools (Scott, 2008), possui ferramentas úteis para a análise de vários aspectos da linguagem. Berber-Sardinha (2004:86) lista alguns de seus usos, entre eles: a composição lexical, a temática dos textos e sua organização retórica e composicional, além de contextos locais (concordâncias/Concord) e dados estatísticos (listas de palavras/Wordlist) que facilitam a visualização de padrões de uso.

A lista de palavras (Wordlist) é utilizada para organizar os corpora em listas que são ordenadas alfabeticamente e por frequência. Com essa mesma ferramenta, podem-se obter dados estatísticos dos textos, como alguns dos mostrados anteriormente - número de palavras (Tokens), número de palavras diferentes (Types), número de orações (Sentence), etc., contribuindo tanto para a organização dos dados estatísticos, como para a análise das palavras utilizadas com mais frequência.

Com a ferramenta Concord, podem-se observar os contextos em que a palavra de busca ocorre através do concordanciador. Nesta ferramenta, a palavra de busca aparece destacada e no centro da tela do programa do texto em que ocorre. Através das listas de concordância é possível estudar o contexto de ocorrência da palavra de busca (o clítico 'se') simultaneamente em todo o corpus.

Ainda nessa ferramenta, é possível utilizar a coluna Set para facilitar o agrupamento das ocorrências. A utilização desse e outros recursos do programa estão detalhados no tratamento das ocorrências.

\section{$4.3 \mathrm{O}$ tratamento das ocorrências}

Foram feitas listas de concordância com os artigos de Linguística, com o uso da ferramenta concord. Foram eliminadas as ocorrências em que o 'se' é uma conjunção, com valor condicional, como no exemplo: 
1. Se verificarmos as diferenças nas duas situações, ou seja, subtraindo-se o número médio de palavras por minuto em pares do número médio de palavras por minuto do teste individual, observamos que $S b$ produziu 4,84\% a mais quando fez o teste individual, Sd, 1,59\% e Si, 8,61\%. (Delta026).

Também foram eliminadas as ocorrências com o processo tratar por não ser o objeto de estudo deste artigo:

2. $\quad$ Trata-se de um caso que aparentemente envolve hiperalçamento de sujeito com resumptivos, mas na verdade não há sujeito hiperalçado na estrutura. (Delta006).

Nota-se que quando esse processo ocorre com o clítico 'se' não tem sentido de cuidar (material: Tratar de um doente) ou falar, discutir (verbal: Tratamos do assunto na reunião), mas sim de ser (relacional).

Após essas exclusões, aplicou-se um teste ${ }^{3}$ nas demais ocorrências que consiste em fazer paráfrases, mudando-as para dois tipos de construção: primeira pessoa do plural e passiva analítica. As ocorrências que permitem essas construções foram agrupadas em um primeiro grupo - denominado 1. Como não são objetos de análise deste artigo, esse grupo não é descrito em maiores detalhes, porém sua descrição se encontra na tese desta pesquisadora. Conforme exemplo:

Ocorrência real:

3. Compara-se neste artigo um conjunto de fatos relacionados a interface sintaxe/morfologia em quatro línguas.... (Delta_006).

Testes:

3'. Comparamos neste artigo um conjunto de fatos relacionados a interface sintaxe/morfologia em quatro linguas....

3. As construções que possuem o número seguido de apóstrofe indicam as construções testes descritas na parte metodológica do artigo. 
3". Foi comparado neste artigo um conjunto de fatos relacionados a interface sintaxe/morfologia em quatro linguas....

As ocorrência que não permitem essas construções foram agrupadas no segundo grupo - denominado 2 .

Casos como o exemplo abaixo não permitem a passiva analítica:

4. É comum afirmar-se que o sistema fonológico ou inventário fonêmico do Português contém uma 'série nasal'12. (Delta_025).

Para facilitar a análise, na coluna set, foram marcados números que correspondem a que grupo a ocorrência pertence - 1 ou 2, por exemplo. Diferentemente dos dois grupos apresentados anteriormente, há ainda um grupo, de ocorrências em que o 'se' tem função reflexiva, como no exemplo:

5. ... o autor se considera dirigindo o foco das atenções.... (Delta020).

Como esses tipos de construções possuem sujeito e o clítico não possui o uso espontâneo procurado, elas foram excluídas, posto que é o mesmo que dizer:

5'...o autor considera ele mesmo dirigindo o foco das atenções.....

No entanto, nem todas as ocorrências do clítico 'se' que parecem ter a função reflexiva foram excluídas, pois parte delas é constituída de verbos ergativos. Na perspectiva ergativa, a variável é a presença ou ausência do agente.

Para saber se uma oração reflexiva permite construção média, testa-se se o verbo permite um par ergativo, como nas construções abaixo: 
Ocorrência real:

6. Já os processos, sob responsabilidade dos alunos, distribuem-se equitativamente. (Delta022).

Testes:

\begin{tabular}{|l|l|}
\hline 6'.Os processos & distribuem-se \\
\hline Meio & Processo \\
\hline
\end{tabular}

\begin{tabular}{|l|l|l|l|}
\hline 6".Os alunos & distribuem & os processos & equitativamente \\
\hline Agente & Processo & Meio & Circunstância \\
\hline
\end{tabular}

As ocorrências que permitem esses tipos de construção foram agrupadas no grupo 3 (médias) e são descritas e analisadas neste artigo com base na Linguítica Sistêmico-Funcional.

4.4 Metodologia de análise

Esta pesquisa tem como base teórico-metodológica a LSF, proposta por Halliday $(1985,1994)$ e Halliday \& Matthiessen (2004), que além de ver a linguagem como um processo social, possui uma metodologia que permite a descrição detalhada e sistemática dos padrões linguísticos.

Para a LSF, a linguagem é vista como um sistema de escolhas em que qualquer escolha feita pelo usuário está condicionada ao contexto. As escolhas feitas em diferentes níveis no sistema linguístico (semântico, léxico-gramatical, fonológico, fonético) são significativas e determinam a criação de diferentes significados.

Através de um instrumento computacional que possui ferramentas que auxiliam a análise quantitativa, podem-se analisar detalhadamente os usos das orações médias em seus contextos de ocorrências, para descrever e analisar seus padrões de uso, o que possibilita um estudo quantitativo, permitindo generalizações 
mais confiáveis. Com já tem sido verificado em grande número de pesquisas como as ligadas aos projetos SAL e Direct ${ }^{4}$ (LAEL/PUCSP), a Linguística de Corpus (LC) fornece um suporte metodológico adequado às pesquisas que utilizam a LSF por também trabalhar dentro de uma visão de linguagem enquanto sistema probabilístico (Berber-Sardinha 2004:34).

Halliday \& Matthiessen (2004:35) explicam que, sendo o sistema gramatical probabilístico por natureza, o uso de corpus torna o estudo quantitativo possível. Está claro que a análise gramatical com o auxílio computacional e as combinações lexicais estão agora alcançando o ponto em que os estudos quantitativos podem ser garantidos usando um número de amostras suficiente para permitir a comparação entre registros diferentes.

Para analisar o clítico 'se', as listas de concordância do programa WordSmith Tools (Scott, 2008) foram observadas e as ocorrências agrupadas nos grupos citados, de acordo com as generalizações baseadas nos diferentes usos e significados do clítico, servindo de ponto de partida para a análise qualitativa com base na LSF, que tem sua origem na etnografia e utiliza uma metodologia que permite uma descrição detalhada e sistemática dos padrões linguísticos.

A metodologia quantitativa é usada, portanto, para servir de ponto de partida e complementar a análise qualitativa, baseada nos pressupostos da LSF, que procura ver o sistema linguístico em termos de sua função na sociedade, portanto entendê-los nos seus contextos para entender as preferências e os significados dos usos e das características das comunidades que as utilizam.

As características das construções médias com o clítico 'se', bem como os seus diferentes padrões de uso são analisadas em artigos científicos, procurando entendê-las no contexto, mas, também, procurando lançar mais luzes sobre as características desse clítico em Língua Portuguesa, em especial, aos professores e usuários de códigos elaborados.

4. Projeto Direct - em direção à linguagem do trabalho, tem como objetivo analisar o uso da linguagem em atividades profissionais. É realizado no Programa de PósGraduação de Linguística Aplicada e Estudos da Linguagem (PUC-SP). 


\section{Discussão e análise dos dados}

Para esta análise, 1000 ocorrências (um terço das ocorrências totais) com a palavra de busca 'se' foram observadas. Esse número corresponde a um terço do número total de ocorrências em bruto, ou seja, todas as ocorrências com se no corpus de Linguística, composto por 30 artigos científicos.

Recorde-se que as perspectivas da transitividade e da ergatividade são noções teóricas que podem ajudar a explorar as características da representação experiencial em qualquer língua. Acredita-se que assim como o francês (Caffarel, 2006), o português pode ser visto por essas duas perspectivas, sendo assim os processos podem ser utilizados em construções médias.

As ocorrências foram observadas e identificaram-se 58 construções médias, o que corresponde a 5,8\% do total das ocorrências analisadas. Essas foram separadas para serem analisadas, procurando detectar as semelhanças e diferenças no que se refere às escolhas léxico-gramaticais, mais especificamente, os itens lexicais que ocorrem em posição de Meio, os tipos de processos mais utilizados e quais são os Agentes "apagados" nos textos.

Em um primeiro momento, observou-se que praticamente todas as ocorrências eram constituídas de processos materiais e o que as diferenciava eram os diferentes usos dos Meios. A maioria dos Meios estava relacionada à discussão de conceitos teóricos, outros à discussão da pesquisa (ou de partes da pesquisa) e a minoria relacionava-se a retomada do objetivo do artigo, com Meios relacionados à pesquisa. Dessa forma, as ocorrências foram agrupadas em 3 categorias, resumidas na tabela a seguir:

Tabela 2: Categorias das construções ergativas no corpus de Linguística

\begin{tabular}{|l|l|l|l|l|}
\hline $\begin{array}{l}\text { Sub-categorias/ } \\
\text { características }\end{array}$ & Freq. (\%) & Processos & $\begin{array}{l}\text { Agentes } \\
\text { "apagados” }\end{array}$ & Exemplos de Meios \\
\hline $\begin{array}{l}\text { A: retomada do } \\
\text { objetivo do artigo }\end{array}$ & 12 & Materiais & $\begin{array}{l}\text { Pesquisador/autor } \\
\text { do artigo }\end{array}$ & $\begin{array}{l}\text { Artigo, trabalho, } \\
\text { estudo }\end{array}$ \\
\hline
\end{tabular}




\begin{tabular}{|l|l|l|l|l|}
\hline $\begin{array}{l}\text { B:discussão da } \\
\text { pesquisa }\end{array}$ & 29.5 & Materiais & $\begin{array}{l}\text { Pesquisador/autor } \\
\text { do artigo }\end{array}$ & $\begin{array}{l}\text { Distribuição, } \\
\text { documentos, análise }\end{array}$ \\
\hline $\begin{array}{l}\text { C: discussão de } \\
\text { conceitos teóricos }\end{array}$ & 58.5 & Materiais & $\begin{array}{l}\text { Pesquisadores } \\
\text { antecessores ou } \\
\text { teóricos da área }\end{array}$ & $\begin{array}{l}\text { Identidades, conceito } \\
\text { de gênero, política } \\
\text { de representação }\end{array}$ \\
\hline
\end{tabular}

Como se pode observar, as categorias possuem o mesmo Agente apagado - o autor do artigo. Porém, esses apagamentos ocorrem em momentos diferentes. Em A, as escolhas dos Meios estão ligados à retomada do objetivo/propósito do trabalho. Enquanto em B estão ligados à discussão dos dados, da teoria ou de hipóteses. Em C, estão relacionadas à discussão de conceitos teóricos.

Como esta análise tem como base a ergatividade, as ocorrências das construções médias são discutidas seguidas da construção efetiva correspondente. Ambas constituem o par ergativo e são analisadas nas categorias a que pertencem.

\section{1 Categoria A: retomada o objetivo do artigo}

Esta categoria é a que possui menor ocorrência (12\% do total de construções ergativas analisadas) e as escolhas dos Meios estão relacionadas à retomada do objetivo do trabalho.

Note-se que as construções efetivas, seguidas por apóstrofe, possuem os mesmos Agentes - o autor/pesquisador. Os participantes (Meta), objetos das construções efetivas: trabalho, artigo, etc. são os Meios das orações médias.

Ao escolher artigo como Meio em uma oração, atribui-se a ele a responsabilidade da ação. Assim, essa oração, chamada de média, representa um processo causado por ele mesmo (self-caused process), sem a participação de um agente (Halliday, 1994:163). Porém, ao ler o artigo, presume-se que o Agente é o autor, mesmo que ele não esteja expresso ou não possa ser retomado no contexto, como pode ser observado nos exemplos adiante: 
6. Este trabalho se organiza do seguinte modo: a seção 1 apresenta motivações semânticas e pragmáticas para a ausência da manifestação formal da valência potencial... (Delta001).

6'. O autor organiza este trabalho do seguinte modo...

7. Este artigo se organiza da seguinte forma: na seção 1, apresentamos os pressupostos formais da teoria gerativa em sua função Regência e Vinculação... (Delta007).

7'. O autor organiza este artigo da seguinte forma: na seção $1 \ldots$

8. ... este artigo se restringe à análise qualitativa de alguns casos especialmente selecionados. (Delta001).

8'. O autor restringe este artigo à análise qualitativa de alguns casos especialmente selecionados.

9. Este artigo se debruça sobre o mapeamento entre os Niveis Interpessoal, Representacional e Morfosintático da gramática... (Delta008).

9'. O autor debruça este artigo sobre o mapeamento entre os Níveis Interpessoal, Representacional e Morfosintático da gramática...

10. O discurso pedagógico, de que neste artigo se cobra maior efetividade em sua função de adequação-apropriação de outros discursos... (Delta030).

10'. O autor cobra neste artigo maior efetividade...

Nessa categoria, há o predomínio de processos materiais (verbos), da ordem do "fazer", porém no último exemplo, o processo cobrar está próximo do verbal (verbos do dizer).

Estudos descritivos da Língua Francesa, como Caffarel (2006:88), já apontam que, na perspectiva da ergatividade, a agenciação está relacionada com o sentido de causação (causation), que é percebida 
mais facilmente nas orações materiais, pois é apenas no campo do "fazer" que o Agente tem o poder físico para agir sobre algo.

Do ponto de vista textual, as escolhas temáticas estão organizadas de forma a apagar o Agente. Sabe-se que a escolha do Tema é um recurso importante para manipular a contextualização de uma oração, pois ele orienta o leitor e, nesses casos, ao tematizar os segundos participantes (Metas) das orações efetivas, seguido do clítico e do processo, se têm Temas não-marcados, ou seja, os participantes são Temas das orações. Esse tipo de Tema é o mais comum, segundo Halliday \& Matthiessen (2004:67). Assim, o participante é o dado, a informação nova localiza-se no Rema e o Agente é apagado.

\subsection{Categoria B: discussões relacionadas à pesquisa}

As ocorrências desta categoria se assemelham à categoria anterior, por também possuírem o mesmo Agente nas construções efetivas. Porém, se diferenciam por não serem usadas para retomar o objetivo do trabalho, pois ocorrem em situações de discussão dos resultados de pesquisa. Assim como a categoria anterior, há um predomínio de processos materiais, como se pode ver nas ocorrências abaixo:

11 . A mesma distribuição se sustenta nas relações estabelecidas pelas preposições por e em, nos exemplos de (20a-b) e (21ab)... (Delta002).

11'. O autor sustenta a mesma distribuição nas relações estabelecidas pelas preposições por e em, nos exemplos de $(20 a-b)$ e $(21 a-b) \ldots$

12. A conexão entre tais domínios se estabelece no momento em que, utilizados como andaimes ou como modelos para a produção do jornal escolar, as escritas desses últimos são tomadas como objeto de ensino nos exercícios mencionados. (Delta003). 
12'. O autor estabelece a conexão no momento em que, utilizados como andaimes ou como modelos para a produção do jornal escolar...

13. ... esses documentos se caracterizam por apresentar uma estrutura temática mais complexa, articulando um agir prescritivo... (Delta005).

13'. O autor caracteriza esses documentos por apresentar uma estrutura temática mais complexa, articulando um agir prescritivo...

Observa-se que os Meios, nas ocorrências 11 e 12, são nominalizações dos processos distribuir e conectar. O uso de nominalizações ocorre em dez ocorrências desta categoria, o que corresponde a $60 \%$. As demais são como a 13 em que o participante tematizado retoma o que foi expresso anteriormente.

As nominalizações resumem eventos mencionados no contexto precedente e é uma expressão com um substantivo que permite que a informação seja empacotada na posição de Tema. Se fosse feito de outra maneira, precisaria de uma oração para ser expressa. É um recurso importante nos textos acadêmicos e científicos, como aponta Halliday \& Martin (1993).

Aagenciação pode ser eliminada através do uso da nominalização, condensando a informação de maneira altamente estruturada. A manipulação dos itens lexicais de forma a colocar a nominalização em posição temática, permite tomar os eventos descritos anteriormente como ponto de partida da nova mensagem.

Thompson (1996:170) denomina encapsulamento quando a nominalização está em posição temática na oração. A nominalização permite que o significado seja tratado como algo que existe, como uma "coisa" abstrata. Ela pode ser um participante de um outro processo, funcionando assim como Tema. O autor (op.cit) discute que esses tipos de construções são comuns em discursos formais em que o significado é trazido em uma oração cheia (full clause) e é encapsulada em uma nominalização que serve como ponto de partida da próxima oração. 
Francis (1994), assim como Thompson (1996), também trata desse fenômeno, chamando-o de rótulo. A autora discute seu papel coesivo nos textos, tratando-o como um procedimento de coesão interfrasal, em que um item lexical ou uma expressão engloba uma extensão de texto que pode precedê-lo ou segui-lo.

\subsection{Categoria C: discussão de conceitos teóricos}

Esta categoria, a mais numerosa $(58,5 \%)$, diferencia-se das apresentadas anteriormente por estar relacionada à seção teórica. Além disso, o Agente, não é o autor do artigo, mas sim um teórico ou um pesquisador antecessor que não é expresso como Agente na resenha e, frequentemente, seus conceitos são colocados em posição de Meio nas orações, como se pode observar nas ocorrências seguintes:

14. Para Hall (1996), as identidades vinculam-se à noção de representação. (Delta004).

14'. O autor [Hall] vincula as identidades à noção de representação.

15. Para Foucault (1975/1986) o exame manteve-se bem próximo do poder disciplinar que o originou, sendo um componente intrínseco das disciplinas. (Delta005).

15'. O autor [Foucault] manteve o exame bem próximo do poder disciplinar que o originou, sendo um componente intrínseco das disciplinas.

$\mathrm{Na}$ perspectiva textual, os temas das ocorrências acima são marcados, pois não coincidem com os sujeitos da oração. As circunstâncias de ângulo do tipo ponto de vista (viewpoint) estão em posição temática. Dessa forma, o elemento que teria sido a escolha não-marcada como Tema, passa a fazer parte do Rema, caso de identidades e exame.

Nas próximas ocorrências, os conceitos abstratos estão em posição temática: 
16. O conceito de gênero se estabelece entre nós como uma ferramenta de teorização e de explanação (cf.:Bunzen, 2006:153) sobre como a imagem funciona associada a objetivos e atividades para criar e recontextualizar interações sociais. (Delta009).

16'. O autor estabelece o conceito de gênero entre nós como uma ferramenta de teorização e de explanação sobre...

17. A nossa consciência individual é exteriorizada pela linguagem, caracterizando-se, dessa forma, como um evento eminentemente social e ideológico, daí o fato de o dialogismo assumir, na teoria bakhtiniana, uma dupla função, como nos indica Brait (1997:98). (Delta020).

17'. O autor categoriza a nossa consciência individual que é exteriorizada pela linguagem como um evento eminentemente social e ideológico...

Observa-se que, nessas construções, os autores (teóricos/ pesquisadores antecessores) ocupariam a posição de Agentes das orações, mais especificamente, seriam os Atores dos processos materiais. Os conceitos discutidos são colocados em posição temática, portanto Temas não-marcados, em que o sujeito é o Tema. Através da observação do contexto maior da ocorrência, é possível observar que a tematização dos conceitos teóricos contribui para a continuidade do Tópico do discurso, desenvolvendo o que foi estabelecido previamente.

Pode-se supor que esses conceitos teóricos, em posição de Meio, nas orações desta categoria, possuem função de rótulos, mais precisamente de rótulos anafóricos que, conforme Francis (1994), são expressões que capturam parte do texto que já ocorreu, porém de forma diferente da categoria $\mathrm{B}$, em que as escolhas em posição de Meio são nominalizações. Como um tipo de repetição que reitera uma informação apresentada anteriormente, como um elo entre o que já ocorreu e o que irá ocorrer. Assim, eles sumarizam, caracterizam 
e apresentam o ponto de vista do autor a respeito do que está em destaque, ou seja, mostrando ao leitor como o autor entende e interpreta determinados conceitos.

\section{Considerações finais}

Embora este artigo analise apenas uma amostra - 1000 ocorrências - em um corpus pequeno de artigos científicos de Linguística, se observou que as construções, vistas pela perspectiva da ergatividade (Halliday, 1985, 1994), podem ser mais bem compreendidas e descritas com base no seu contexto de uso. A escolha dos Meios e, principalmente, suas características, permitiram chegar a três categorias distintas de análise.

A maioria das ocorrências está relacionada à discussão de conceitos teóricos e se pode pressupor que os autores, ou pesquisadores sucessores, "apagados" foram citados anteriormente de forma indireta, em orações com circunstâncias de ângulo ou, ainda, colocados em parênteses em final de períodos nos artigos. As demais ocorrências estão relacionadas à apresentação do artigo e à discussão de resultados obtidos, sendo utilizadas, portanto, para explicar como o artigo está organizado, seus objetivos, sua organização e, também, apresentar os resultados obtidos juntamente com a reflexão do autor sobre a pesquisa.

Sabe-se que a linguagem acadêmica é caracterizada por seu caráter sintético e objetivo e essas construções permitem compreender a relação de modéstia estabelecida no texto, exigência do gênero e da linguagem elaborada. Apesar de os artigos de Linguística serem muitas vezes escritos na primeira pessoa (singular ou plural), a análise mostra que há momentos em que os participantes são apagados no texto. Este parece ser um recurso utilizado no gênero de estudo que prima em ser sintético e impessoal.

Espera-se que este estudo tenha contribuído para a descrição dos usos das construções médias na área de Linguística, para os estudos sobre gêneros acadêmicos em geral e, também, para o planejamento 
de cursos instrumentais de Língua Portuguesa para graduandos e pósgraduandos de Letras, tendo como foco a linguagem acadêmica.

Em trabalhos futuros, pretende-se analisar um número maior de construções médias, com base na perspectiva da ergatividade, para verificar se, em outras áreas do conhecimento, esses usos também são encontrados, comparando esses usos nas diferentes áreas de conhecimento.

Recebido em: julho de 2013 Aprovado em: setembro de 2013 caricari@terra.com.br

\section{Referências bibliográficas}

ANDERSON, S. On the notion of subject in ergative languages. In: Li. C. (Ed.). Subject and topic. New York: Academic Press,1976.

BARBARA, L. \& MACEDO, C.M.M. Processos verbais em artigos acadêmicos: padrões de realização da mensagem. In: Barbara, L. \& Moyano, E. (org). Textos e linguagem acadêmica. Campinas-SP: Mercado de Letras, 2010.

BERBER SARDINHA, T. Linguística de Corpus. Barueri-SP: Manole, 2004.

CAFFAREL, A. A systemic functional grammar of french. Londres: Continuum, 2006.

DIXON, R. M. W. 1994. Ergativity. Cambridge University Press, 1994.

FRANCIS, G. Labelling discourse: an aspect of nominal group cohesion, in Coulthard, M. (ed) Advances in Written Text Analysis. London: Routledge, 1994.

HALLIDAY, M.A.K. An Introduction to Functional Grammar. Londres: Edward Arnold, 1985.

HALLIDAY, M. A. K. \& MARTIN, J. R. Writing sciece: literacy and discursive power. Londres: Falmer, 1993.

HALLIDAY, M. A. K. An introduction to Functional Grammar. Londres: Edward Arnold, 1994 
HALLIDAY, M. A. K. \& MATTHIESSEN, C.M.I.M. An introduction to Functional Grammar. Londres: Edward Arnold. Third Edition, 2004.

MANNING, C. D. Ergativity - argument structure and grammatical relations. Stanford: CSLI Publications, 1996.

MARTIN, J. R. \& WHITE, P. R. R. The language of evaluation: Appraisal in English. London: Palgrave/Macmillan, 2005.

MORAIS, F. B. C. Análise comparativa das conclusões de artigos científicos das áreas de odontologia e lingüística. In: Barbara, L. \& Moyano, E. (org). Textos e linguagem acadêmica. Campinas-SP: Mercado de Letras, 2010.

MORAIS, F. B. C. Entre alhos e bugalhos - os usos do clítico se na escrita acadêmica. Tese de doutorado inédita. PUC-SP, 2013.

MOYANO, E. I. La discussión de los artículos de investigación en el area de la agronomia: reconsideración de su estructura desde el análisis del discurso. In: Barbara, L. \& Moyano, E. (org). Textos e linguagem acadêmica. CampinasSP: Mercado de Letras, 2010.

SCOTT, M. R. Wordsmith Tools. Software for text analysis. Oxford: Oxford University Press, 2008.

THOMPSON, G. Introducing functional grammar. Londres: Arnold, 1996.

VIVAN, E. Principais usos de processos verbais e metáforas interpessoais em artigos de Linguística aplicada. Tese de doutorado inédita. PUC-SP, 2010. 